\title{
Organizational Change as an Essential Part of Human Resource Management
}

\author{
Joanna Gajda \\ Czestochowa University of Technology, Częstochowa, Poland
}

\begin{abstract}
This article attempts to describe the conditions in which the modern organizations operate. The focus is primarily on the role and importance of organizational change. Currently an important feature of operating in the market is constant adjustment to the expectations of external environment, but also listening to the expectations of organization's members. Also, the role and importance of management in initiating and implementing change is highlighted. Simultaneously, based on the literature, an analysis concerning the reaction of employees to the changes was made. Effective change is one that is accepted by all members of the organization and all members have to engage in its implementation. Therefore, the article highlights the role and importance of proper motivation of employees to willingly accept changes proposed by the management.
\end{abstract}

Keywords: organizational change, motivation, human resources management, environment, employee

\section{Introduction}

Companies operating in open market were created as a result of actions taken by people. Thus, in enterprises requiring changes, the conviction that the personal involvement of enterprising employees will enable the company to take difficult projects should dominate. In striving for success, the company must respond to a changing environment while making transformations in its own structure. The currently applicable management concepts, while stressing the importance of human factors, indicate the need for initiating and preparing actions aimed at changes basing on the use of human resources. So defined objectives imply the development of companies in various fields and development of workers, because they determine what to keep and what should be modified. This article presents selected factors inherent in the enterprise, which, when taken into account and implemented in the process of change, allow achieving a high level of efficiency.

\section{The Need to Implement Organizational Change in Response to Environmental Change}

Increasing globalization demands an immediate response from the company to the progressive rate of implementation of changes in the functioning of its internal structures. Well-known statement by Druker (1991) saying that "the only constant thing in modern enterprises is change" met with a positive response from the scientists. It is worth quoting the statement of Fabiańska and Rokita (1986), who asserted that the basic development tasks rely on the continuous increase in the economy's ability to meet business and social needs through implementing changes. Emphasizing the importance of these considerations, one should point out the

Joanna Gajda, Ph.D., Czestochowa University of Technology, Częstochowa, Poland.

Correspondence concerning this article should be addressed to Joanna Gajda, Bialska 59/3, 40-200 Częstochowa, Poland. 
need for changes in the internal environment of the company in response to the changes taking place in a complex market environment. It should be noted that a change occurs in the company, when something is becoming useless and inconsistent with current requirements. It becomes obvious that engaging in actions aimed at organizational change brings tangible benefits in the form of successful development of the company, which is strongly reflected in achievement of competitive advantage.

Companies operating in the market are open systems, which mean that they are directly related to the environment. Both sides - the company and the market environment remain in continuous interaction and equally influence each other. According to Kożusznik (2011), who quoted A. Rice, relationships among them are based on the fact that companies import resources from market environment, then use them at the stage of processing, and return them to the environment as certain goods and services. Everything that happens in the modern environment, especially changes occurring at a rapid pace, has an impact on the functioning of the organization, which means that they must be taken into account in planning its development strategy (Grzesiuk, 2010).

It must be remembered that the changes also come from the company itself, which can demonstrate the ability to implement them only if its components, meaning people, structure, and systems, are ready and open to the implementation of changes. Thus, the effective management of changes encompasses planned actions aimed, inter alia, at human resource management (Gabrielczak, 2012). In order to increase the possibility of achieving the desired results in the implementation of adaptation and modernization changes, it is recommended to plan and carry out activities in the area of human resource management at all stages. Human resource management is not only an operational activity, but also a strategy which is based on the proceedings intended to contribute to recruitment, retention, and development of the staff. Having adequate capacity within the organization becomes a requirement, because of the need to maintain harmony with changing environment in which the organization operates (Clarke, 1997). Consequently, it is assumed that the integration of the overall strategy of the organization with a strategic approach to human resources management can bring several benefits, especially increase in profitability of business activity (Król \& Ludwiczyński, 2006).

\section{Factors Determining the Success of the Implementation of Adaptation and Modernization Organizational Changes in the Area of Human Resource Management}

Any solutions aimed at effectively implementing changes in the internal environment of the organization, depend on people management concepts that are visible in the implementation of the human resource function. Personal sphere is closely related to people and work performed for the increase in economic activity of the company. The correctness of the process of change will ensure the proper functioning of procedures regarding human resources planning, recruitment, and selection of staff. Serious treatment of these issues is conducive to improving the situation of the organization in the face of change. Therefore, it is recommended that managers appropriately direct the course of the process of obtaining workers, because their knowledge and skills will determine whether the company will achieve efficiency in implementing the changes. The activities undertaken by the organizations to implement needed changes often involve the adaptation of acquired employees during recruitment to new working conditions. The factor of human resource management, that allows to prepare employees to accept their tasks, necessary for the effective implementation of the changes, is motivation. Those responsible in the company for facilitating the adaptation of new employees to the working environment utilize various types of incentives that are meant to increase the efficiency of employees and achieve the expected high 
level of performance (Armstrong, 2011). In this context, the positive effects of the process of adjusting the employee to work are gained through specific strategies. The strategy involves presenting in a concise way what should be done to enable the organization to effectively carry out its own vision of change (Harvard Business Essentials, 2003). There is no universal strategy that could be used. The choice depends on many factors - both internal and external, namely, vision, mission, and strategic objectives. Literature provides many proposals for the use of strategies in specific areas of business management. People can distinguish a few types of strategies, such as horizontal and vertical integration, diversification, and narrowing the field of activity or development (Orłowski, 2010). Bylok (2004) pointed to the role of the two opposing strategies in the process of occupational adaptation. One of them is a strategy - throwing into cold water. Its purpose is to give employees tasks to be implemented on the first day of work at a given position without the possibility of obtaining help from others. This strategy enables the development of entrepreneurship and independence of employee in implementing the tasks. The development of individual potential of employee is based on the "water test". This method also provides assistance from a superior to a subordinate, but it is difficult to determine at what point it would occur. It is important that the employee was instructed on how to implement the task timely and not fail, which could cause a negative attitude towards further work. The second is the strategy-now, involving the gradual introduction of subordinates to the tasks assigned to them from the first moments of work at their given position. The advantage of this method is that the employee during the first days of a new job is not overloaded with too complex tasks, but instead it is allowed to watch how others competently perform tasks entrusted to them (Bylok, 2004). As pointed out by Lichtarski (2003), in preparations for the development of change management strategies, it is important to not only focus on the employee, but to the same extent on the job, objectives, and development of a suitable methodology. The strategy that focuses attention on the man is looking for solutions to create the circumstances to facilitate the implementation of the process of change. A strategy to determine the tasks to be performed attempts to give an answer to the question of what is the essence of change and in which direction it should go. In this case, it is important to link the tasks with psychosocial determinants to improve the efficiency of the process. The strategy that focuses on the methodological actions points to the ways and tools to adapt to the changes and implement them effectively (Lichtarski, 2003). In circumstances marked by great uncertainty, it is necessary to stimulate appropriate attitudes of employees focused on creating an internal desire to achieve certain objectives, which in turn leads to a more effective implementation of organizational changes. Due to the introduction of changes, employees are required to show emotional maturity expressed in the ability to show flexibility while maintaining the stability of personality. Emotional maturity is closely linked to a sense of control over one's actions (Sikorski, 1998). A sense of control can be external and internal. The external sense of locus of control occurs, when a man sees reasons for decisions concerning his actions in the random factors (trust in fate and faith in other people), and not in the ability to use his own predispositions (Brytek, 2007). From the theory of Rotter, it can be concluded that a man with a sense of internal control forms a positive attitude to the uncertain reality, feels responsible for implementing his own actions, is tenacious even in the face of present difficulties, and is not discouraged but focuses on his core skills (Sikorski, 1998). Adapting to a new situation marked by a high degree of uncertainty strengthens the organizational culture. Only a culture characterized by high resistance to the uncertainty can be a base for changing implementation process. The development of this type of culture is heavily affected by employees. A great convenience for the creation of culture acting as a catalyst for change is the situations in which workers "will not feel the increase in independence as the need to work more for the company for which 
they would not receive adequate compensation, but as a fulfillment of an essential condition for achieving their personal goals" (Grzesiuk, 2010, p. 150). This claim is a reference to the theory of achievement motivation. In this approach, a man shows tendency to incur the effort to change as soon as he becomes convinced that he is able to achieve whatever he wants. In the case of organizational changes taking place, particular importance is attributed to management. It largely depends on management whether the employees will gain confidence in their own abilities and take on the risks associated with engaging in the process of change. Kaczmarek (2004, p. 36) noted that the task of management is to create conditions "to stimulate and develop the creativity of employees, reveal their talents and creativity, as well as letting them believe in their own abilities, which would increase accountability and motivate them to further achievements and personal fulfillment". An important motivating factor for the inclusion of employees in the change process is a reward. Its motivational function manifests itself in the stimulating impact on the behavior of the employee during work (Nogalski \& Śniadecki, 2009). An important element of reward is pay. Several significant issues are linked with the implementation of the incentive function of rewards (Jasiński, 2007):

(1) Payroll should create the conditions in which actions taken to carry out given tasks are attractive to employees, because of the possibility of obtaining the values cherished by them.

(2) Attitude of employees depends on three factors:

- assessment of the extent to which the wages meet their needs;

- whether they feel that the pay was adequate;

- whether the relation between wages and work is adequate.

Motivating employees through the pay requires the managers to have broadly defined skills - psychological knowledge and understanding of human needs. The manager has an impact on shaping and improving the behavior of subordinates through the selection and proper application of the rules of motivation. This is conducive to improving their approach to the tasks and identifying with the objectives set by the organization for the implementation of changes (Szczupaczyński, 1995). The importance of money is determined largely by the individual needs of employees and their expectations. Thus, with the help of wages, it is possible to influence the attitudes and behavior of the staff in order to encourage achieving high results (Kopertyńska, 2015).

In the process of implementation of tasks related to the implementation of organizational change, training plays an important role. Training has a clear effect on the ability of subordinates to adapt to a new work environment and growth of the company. Organization of training courses aims to equip employees with new knowledge and skills and complement the existing gaps in the requirements for a specific workplace, as well as the acquisition of soft skills associated with personality predispositions. The company that is focused on encouraging employees to participate in training courses strives to meet its own expectations for the implementation of the human resources function in case of a change. Factors listed above translate into positive effects resulting from the active participation of people in the implementation of the process of change. Involvement in the project and intellectual progress are important elements that make up a business model which is capable of introducing new solutions aimed at active implementation of changes. In a company where there is a good climate conducive to changes, a feedback occurs in the form of a loop of positive reinforcement. According to Grzybowska (2010), reinforcing loops lead to a gradual growth and as a result the pace of change is accelerating because the individual elements of a company begin to reinforce. If, however, a situation arises in the organization that causes unfavorable conditions to change and this change will be enforced by managers, 
it will not be meet with understanding and interest among the staff. This is an example of a company unable to implement a change, in which all the components of the loop affect the creation of a negative cycle. This case is a proof that the reinforcing loop is negative, which means that it is characterized by the increasing pace and a sharp drop. Among the characteristics of the negative loop are ignoring the needs of the enterprise, distrust and lack of understanding of a change, deepening prejudice, and resistance to change (Grzybowska, 2010).

\section{Reactions of Employees to Changes and the Ways of Executives in Overcoming Resistance to Change}

The changes inside the company influence the employees. This means that one must reckon with their reaction to changes. Everyone reacts in a different way, which is reflected in one's attitude. This can have a negative impact on professional status, qualifications, and functions. It should be kept in mind that different responses to the changes depend on such factors as individual perception, human sensibility, and anticipation of the effects of actions (Dobrzański, 2008).

People in the face of change present extreme attitudes - from enthusiasm and acceptance of the changes to the fear, terror, and resistance to change. Based on a review of literature on the subject of reactions of people to change, Osbert-Pociecha (2011) pointed to the diversity of feelings, thoughts, and behaviors in the presented cycle of change which consists of six stages. At the first stage, called the loss, the employees take note of the fact that the company will have to apply the necessary changes, but regardless of whether this change will bring something significant to the company they will feel regret for what might be lost. The second stage brings doubt - people think that the decision to abandon the pre-existing status quo was unfounded. In addition, their attitude is characterized by intense search for justifications that would confirm the futility of the change. The third stage is associated with the appearance of discomfort, which is reflected by slowly becoming familiar with the idea that the company must be transformed. The next step is discovering things that are associated with organizational change. The fifth stage comes down to forward-looking and taking control over the new situation, which in turn becomes the prelude to understanding the need of change. At the final stage, the employee has matured to a state of full consciousness that the company is facing inevitable changes.

In view of the above analysis, it seems obvious that it is important for the management to recognize the types of reactions of employees and assign them appropriate roles, so that they will not see the changes as traumatic experiences (Zawadzka, 2006). As business practice shows, high efficiency is achieved with procedures actively engaging the employees in finalization of changes. It is not without a reason that the top management plays a special role. Managers at various levels should supervise the process of change in order to avoid difficulties that may arise from the clash of personalities of employees. Stressing the importance of their role, they need to demonstrate a great deal of patience and especially psychological knowledge (Mendel, 2008). Speaking about the need to successfully carry out changes in the company, managers of change should not be indifferent to issues concerning the development of friendly atmosphere in the workplace. Therefore, the concept of internal marketing is reasonable, because it assumes that in order to effectively carry out changes in the company, one have to build awareness of the common objectives, the involvement of employees in the cooperation, and concern for the proper conduct of the relationship among them, so that they will demonstrate the ability to provide high quality services to each other. As a result of such understood comfort in case of a change, the internal communication system, which is becoming more and more important, should be noted. It is a communication system that will bring out the specificity of the organization in the conditions of change. 
Therefore, it is necessary to find effective ways for individual and group communication to be evaluated and modified. It is important for organizations having the ability to change to develop mechanisms to enable the communication from top to bottom, and on all levels in a regular and systematic way (Grzesiuk, 2010). An information system that allows the transfer of information concerning the vision, goals, and foreseen actions is of great help in the process of change (Kasprzak, 2000). It is worth mentioning the solutions that originate from the idea of kaizen, called suggestion system. This system is based on providing information to subordinates about the advisability and necessity of submitting proposals for the implementation of changes in specific workplace (Cierniak-Emerych \& Gableta, 2007). In the literature, attention is paid to the increased need for early information, especially on the stage of introduction of a change. It should be taken into account that informing employees too late can contribute to discouraging them, cause surprise, and even problems with implementation of a change. At the stage of introduction of a change, an interpersonal communication is required. Managers involved in the change process should inform all persons whose changes concern about successes and failures. What is important, successful change leads leaders to notice the extent of participation of subordinates in solving problems related to the implementation of a change (Potocki, 2009).

\section{Conclusions}

Currently, changes are inherent in the business. To enable the organization to actively participate in the market, it must adapt to the demands of the environment. It should be kept in mind that the changes do not take place spontaneously. Without the organizational capacity, there can be no way of taking the change in the right direction. The most effective stimulators of change are units participating in the execution of this difficult project. Thanks to people who are open and sensitive to the proposals for the modernization of the internal structures of the organization, the change has a chance of success. Regardless of the strategy which the company will use, it is essential to prepare human resources for carrying out the changes. In order to keep the competitive edge, the preparations should take into account business factors, as this will be positively reflected in the efficiency of the implementation of changes. In this process the resistance to change appears, hence the importance of the participation of managers in taking effective measures to overcome this phenomenon.

\section{References}

Armstrong, M. (2011). Human resources management. Warsaw: Wolters Kluwer Business Publishing House.

Brytek, A. (2007). Locus of control and expression of anger in women with bulimia-A pilot survey. Psychotherapy, 1(140), 52.

Bylok, F. (2004). Management of employment in the process of company restructuring. In C. Glinkowski (Ed.), Management of a change. Restructuring of firms in the strategy of economic development of the countries of Central and Eastern Europe (pp. 252-265). Warsaw: Scientific and Technical Publishing House.

Cierniak-Emerych, A., \& Gableta, M. (2007). The share of production workers involved in decision making. Retrieved from https://www.infona.pl/resource/bwmeta1.element.718235f1-b882-3e42-80c6-e33a22df9c6a

Clarke, L. (1997). Management of a change. Warsaw: Gebethnerand Co.

Dobrzański, K. (2008). Formation of human resources in the restructuring of the organization. In K. Zimniewicz (Ed.), Changes in the organization-Causes and consequences (p. 47). Poznan: Scientific Papers of the University of Economics in Poznan.

Druker, P. (1991). The practice of management. Kraków: Reader-Modernity—Kracow University of Economics.

Fabiańska, K., \& Rokita, J. (1986). Planning the development of the company. Warsaw: Polish Economic Publishing House.

Gabrielczak, P. (2012). Managing change as a permanent part of the economic policy of the company. Łódź: "Piktor" Publishing House.

Grzesiuk, K. (2010). Managing change in the aspect of human functioning in business. In K. Machowicz (Ed.), Critical aspects of the contemporary relationship between man and business (p. 150). Lublin: Catholic University of Lublin. 
Grzybowska, K. (2010). Reorganization of the enterprises. Managing organizational change. Poznań: Poznan University of Technology.

Harvard Business Essentials. (2003). Managing change and transition period. Warsaw: MT Business.

Jasiński, Z. (2007). Motivation in the company. The release of human productivity. Material, organizational, and psychological motivators. Warsaw: Placet Publishing House.

Kaczmarek, B. (2004). Changes in the organizational culture of the modern enterprise. In K. Ciejpa-Znamirowski and M. Pawlak (Eds.), Modern companies and financial systems in the process of innovative changes (p. 36). Lublin: Catholic University of Lublin.

Kasprzak, P. (2000). Effective reorganization of the company. Manager, 2000(3), 30.

Kopertyńska, W. (2015). Incentive system in the organization. Retrieved from http://www.wiedzainfo.pl/wyklady/120/system_motywacyjny_w_organizacji_ii.htmlz

Kożusznik, B. (2011). Human behavior in the organization. Warsaw: Polish Economic Publishing House.

Król, H., \& Ludwiczyński, A. (2006). Human resources management. Warsaw: Polish Scientific Publishers.

Lichtarski, J. (2003). The change management strategies. Journal of Organization Review, 2003(9), 10-12.

Mendel, T. (2008). Contribution to study the impact of changes in the environment on the management of enterprises. In K. Zimniewicz (Ed.), Changes in the organization-Causes and consequences (p. 80). Poznan: Scientific Papers of the University of Economics in Poznan.

Nogalski, B., \& Śniadecki, J. (2009). "The greatest good" in the context of unethical management of the organization. An attempt for the identification and diagnosis. Scientific Papers of the University of Economics in Wroclaw, 2009(42), 223.

Orłowski, W. (2010). Investment processes and strategies of enterprises in times of crisis: Research report. Warsaw: Polish Agency for Enterprise Development.

Osbert-Pociecha, G. (2011). The ability to change as a driving force of flexibility in the organization. Wrocław: University of Economics in Wroclaw.

Potocki, A. (2009). The role of communication in shaping the organizational changes in the company. Scientific Papers of the University of Economics in Krakow, 2009(801), 12.

Sikorski, C. (1998). People of new organization. Patterns of organizational culture and high tolerance to uncertainty. Lodz: University of Lodz.

Szczupaczyński, J. (1995). Basics of management and managing people in organizations. Warsaw: International School of Managers.

Zawadzka, L. (2006). Contemporary issues and selected issues of economic systems modeling. Gdansk: Gdansk University of Technology. 